\title{
A new member of the fusaricidin family - structure elucidation and synthesis of fusaricidin $E$
}

\author{
Marcel Reimann ${ }^{1}$, Louis P. Sandjo ${ }^{1,2}$, Luis Antelo ${ }^{3}$, Eckhard Thines ${ }^{3,4}$, Isabella Siepe ${ }^{5}$ \\ and Till Opatz*1
}

\author{
Full Research Paper \\ Address: \\ ${ }^{1}$ Institute of Organic Chemistry, Johannes Gutenberg-University, \\ Duesbergweg 10-14, 55128 Mainz, Germany, ${ }^{2}$ Departamento de \\ Ciências Farmacêuticas, Centro de Ciências da Saúde, Bloco J/K, \\ Universidade Federal de Santa Catarina, Florianópolis 88040-900, \\ SC, Brazil, ${ }^{3}$ Institute of Biotechnology and Drug Research, Erwin \\ Schrödinger-Str. 56, 66776 Kaiserslautern, Germany, ${ }^{4}$ Institute of \\ Molecular Physiology, Microbiology and Wine Research, Johannes \\ Gutenberg University Mainz, Johann-Joachim-Becher-Weg 15, 55128 \\ Mainz, Germany and ${ }^{5}$ BASF SE, 67056 Ludwigshafen, Germany \\ Email: \\ Till Opatz - opatz@uni-mainz.de \\ * Corresponding author \\ Keywords: \\ cyclodepsipeptides; fusaricidins; lipopeptides; structure elucidation; \\ total synthesis \\ Beilstein J. Org. Chem. 2017, 13, 1430-1438. \\ doi:10.3762/bjoc. 13.140 \\ Received: 03 May 2017 \\ Accepted: 07 July 2017 \\ Published: 20 July 2017 \\ This article is part of the Thematic Series "Lipids: fatty acids and \\ derivatives, polyketides and isoprenoids". \\ Guest Editor: J. S. Dickschat \\ (C) 2017 Reimann et al.; licensee Beilstein-Institut. \\ License and terms: see end of document.
}

\begin{abstract}
Two hitherto unknown fusaricidins were obtained from fermentation broths of three Paenibacillus strains. After structure elucidation based on tandem mass spectrometry and NMR spectroscopy, fusaricidin E was synthesized to confirm the structure and the suggested stereochemistry. The synthesis was based on a new strategy which includes an efficient access to the 15-guanidino-3hydroxypentadecanoyl (GHPD) side chain from erucamide.
\end{abstract}

\section{Introduction}

Fusaricidins are lipid-modified non-ribosomal cyclic hexadepsipeptides containing four D-amino acids and two L-amino acids. All of them carry an L-threonine linked to a unique 15-guanidino-3-hydroxypentadecanoic acid side chain through the $\mathrm{N}$-terminus. This particular $\omega$-functionalized lipid side chain is of key importance for the antibiotic activity of the fusaricidins and their selective inhibition of bacterial cells due to the interaction with phospholipid cell membranes [1]. Genetic analysis of the producing organisms suggests that the biosynthesis of this essential part of the fusaricidins most likely shows similarity to the fatty acid synthesis pathway [2].

All fusaricidins have three amino acids (L-Thr, D-allo-Thr, and D-Ala) in common and are mostly isolated in pairs which differ in a single amino acid (asparagine vs glutamine). There are several known members of the fusaricidin family which were isolated from several strains of Paenibacillus polymyxa [3,4]. Fusaricidins exhibit antimicrobial activity against Gram-posi- 
tive bacteria and a wide range of fungi including Leptosphaeria maculans, a plant pathogenic fungus responsible for the blackleg disease on Brassica crops [5-7].

Two new compounds were obtained from fermentation of Paenibacillus sp. strain Lu16774 as an inseparable mixture of two homologous cyclic depsipeptides containing either glutamine (in 1) or asparagine (in 2). Initially, the absolute and relative configuration of the isoleucine residue was unknown (Figure 1). Thus, an assumed stereoisomer (containing D-alloIle) of the new fusaricidin member was synthesized based on analogy to known members of the series and compared to the natural product [8].

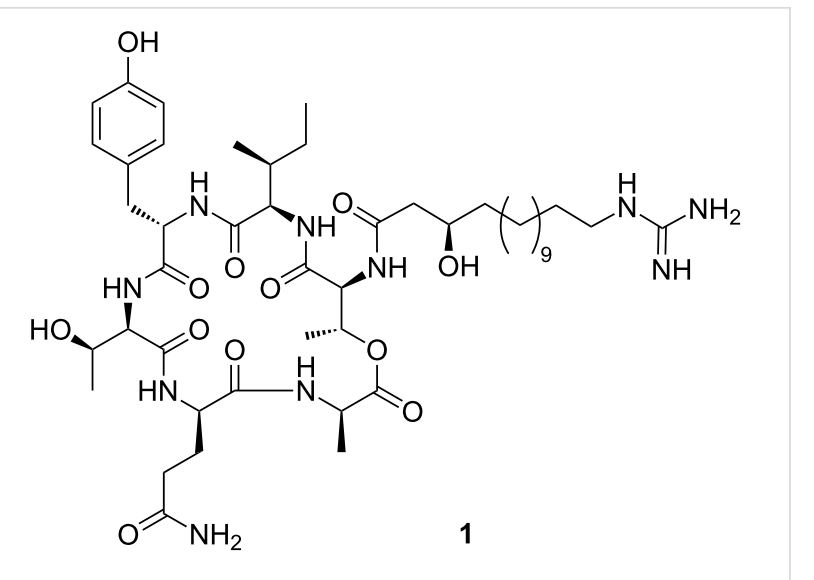

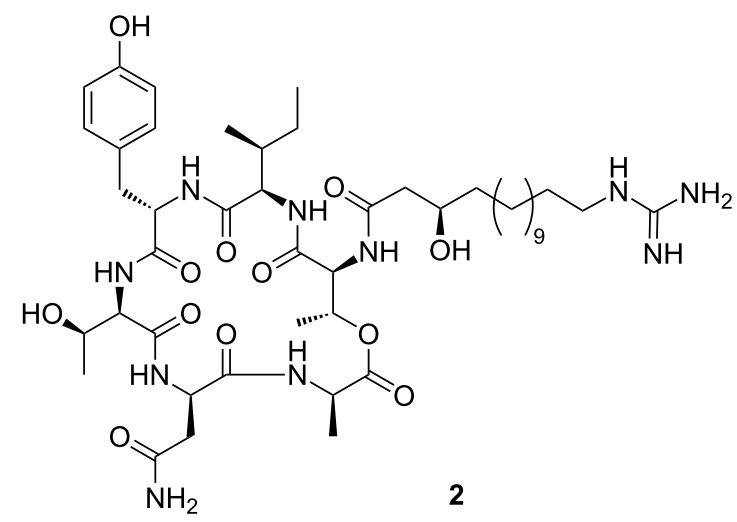

Figure 1: Structure of fusaricidins $E(1)$ and $F(2)$.

\section{Results and Discussion Isolation and structure elucidation}

The Paenibacillus strain was cultivated on agar plates containing GYM medium (10 g/L glucose, $4 \mathrm{~g} / \mathrm{L}$ yeast extract, $10 \mathrm{~g} / \mathrm{L}$ malt extract; $\mathrm{pH} 5.5$, adjusted before autoclaving) and $20 \mathrm{~g} / \mathrm{L}$ agar. The submerged cultivation was carried out for 10 to 20 days at room temperature. For maintenance, agar slants containing the same medium were used and stored at $4{ }^{\circ} \mathrm{C}$. Small scale liquid cultures $(250 \mathrm{~mL}$ GYM medium in $500 \mathrm{~mL}$ flasks $)$ were inoculated with 4-5 pieces of a well grown agar culture and cultivated on an orbital shaker at $120 \mathrm{rpm}$ at room temperature. Large scale fermentations were carried out in $20 \mathrm{~L}$ fermenters with $15 \mathrm{~L}$ GYM medium inoculated with $250 \mathrm{~mL}$ well grown liquid culture at room temperature with agitation (120 rpm) and aeration ( $3 \mathrm{~L} / \mathrm{min}$ ) for 5 to 8 days. To prevent excessive foaming, a few $\mathrm{mL}$ of silicone antifoam were added prior to sterilization of the medium.

An equal volume of isopropanol was added to the culture. After agitation for $2 \mathrm{~h}, 200 \mathrm{~g} / \mathrm{L}$ sodium chloride was added to the mixture until phase separation of the organic and aqueous phase was visible. The isopropanol layer was concentrated in vacuo. The resulting extract was dissolved in methanol, centrifuged for better precipitation of salt residues, and the organic phase was concentrated in vacuo again. This step was repeated until no further salt precipitates were visible.

A portion of the extract $(30 \mathrm{~g})$ was dissolved in methanol and adsorbed to silica gel (Merck, K60, 70-230 mesh, $50 \mathrm{~g}$ ), dried at $40{ }^{\circ} \mathrm{C}$ and applied onto silica gel $(1 \mathrm{~kg}$, column $10 \mathrm{~cm}$ diameter, $30 \mathrm{~cm}$ height). Elution was carried out in four steps as follows: ethyl acetate, ethyl acetate/methanol $(3: 1, v / v)$, ethyl acetate/methanol $(1: 1, \mathrm{v} / \mathrm{v})$ and methanol. The third fraction containing the active compounds, was dried in vacuo and dissolved in $40 \%$ methanol $(\mathrm{MeOH})$ in $0.1 \%$ formic acid (FA, concentration: $100 \mathrm{mg} / \mathrm{mL})$. The other fractions were discarded. A fraction $(20 \mathrm{~mL})$ of the sample was loaded onto a previously equilibrated (with $40 \% \mathrm{MeOH}$ in $0.1 \%$ FA) Chromabond HR-X cartridge (Macherey-Nagel, $1000 \mathrm{mg}$ ). The cartridge was washed with $100 \mathrm{~mL} 40 \% \mathrm{MeOH}$ in $0.1 \% \mathrm{FA}$ and eluted with $60 \mathrm{~mL} 70 \% \mathrm{MeOH}$ in $0.1 \% \mathrm{FA}$. The sample was dissolved in DMSO (concentration: $200 \mathrm{mg} / \mathrm{mL}$ ) and $300 \mu \mathrm{L}$ thereof were applied to a Sunfire C18 column $(19 \times 250 \mathrm{~mm}, 5 \mu \mathrm{m}$, Waters $)$ and eluted as follows: $16 \mathrm{~min}$ at $10 \mathrm{~mL} / \mathrm{min}$, isocratic $70 \%$ $0.2 \% \mathrm{FA} ; 30 \%$ acetonitrile $(\mathrm{MeCN}), 1 \mathrm{~min}$ at $14 \mathrm{~mL} / \mathrm{min}$, gradient to $65 \% 0.2 \% \mathrm{FA} ; 35 \% \mathrm{MeCN}, 5 \mathrm{~min}$ at $14 \mathrm{~mL} / \mathrm{min}$, isocratic $65 \% 0.2 \% \mathrm{FA} ; 35 \% \mathrm{MeCN}$. The five resulting fractions were dried in vacuo and re-dissolved in DMSO (concentration: $125 \mathrm{mg} / \mathrm{mL}$ ). Further purification was performed using the same column and isocratic conditions (flow: $10.5 \mathrm{~mL} / \mathrm{min}$ ) adjusted for every fraction (12.5 mg per run). In the second fraction $68 \% 0.2 \% \mathrm{FA} ; 32 \% \mathrm{MeCN}$ was used and a single peak was detected, consisting of an inseparable mixture of two novel fusaricidins which were named fusaricidin E (1) and fusaricidin F (2). The mixture (6.0 mg) was composed of 3 parts of 2 and 7 parts of its higher homologue $\mathbf{1}$ and had an optical rotation of $[\alpha]_{\mathrm{D}}{ }^{25}+20.9\left(c 0.6\right.$, DMSO- $\left.d_{6}\right)$. The mass difference between both metabolites is $14 \mathrm{amu}$. This observation was supported by two ion peaks observed in the ESIMS spectrum at $\mathrm{m} / z$ 961.6 and $m / z$ 975.6, respectively. 
Through extensive analysis of the 1 and 2D NMR data of the major component $\mathbf{1}$, six amino acids including tyrosine (Tyr), glutamine (Gln), alanine (Ala), two threonines (Thr1 and Thr2) and isoleucine (Ile) were identified. NMR experiments like COSY, NOESY and HMBC (Figure 2) clarified the sequence of the amino acids through two or three bonds correlation.
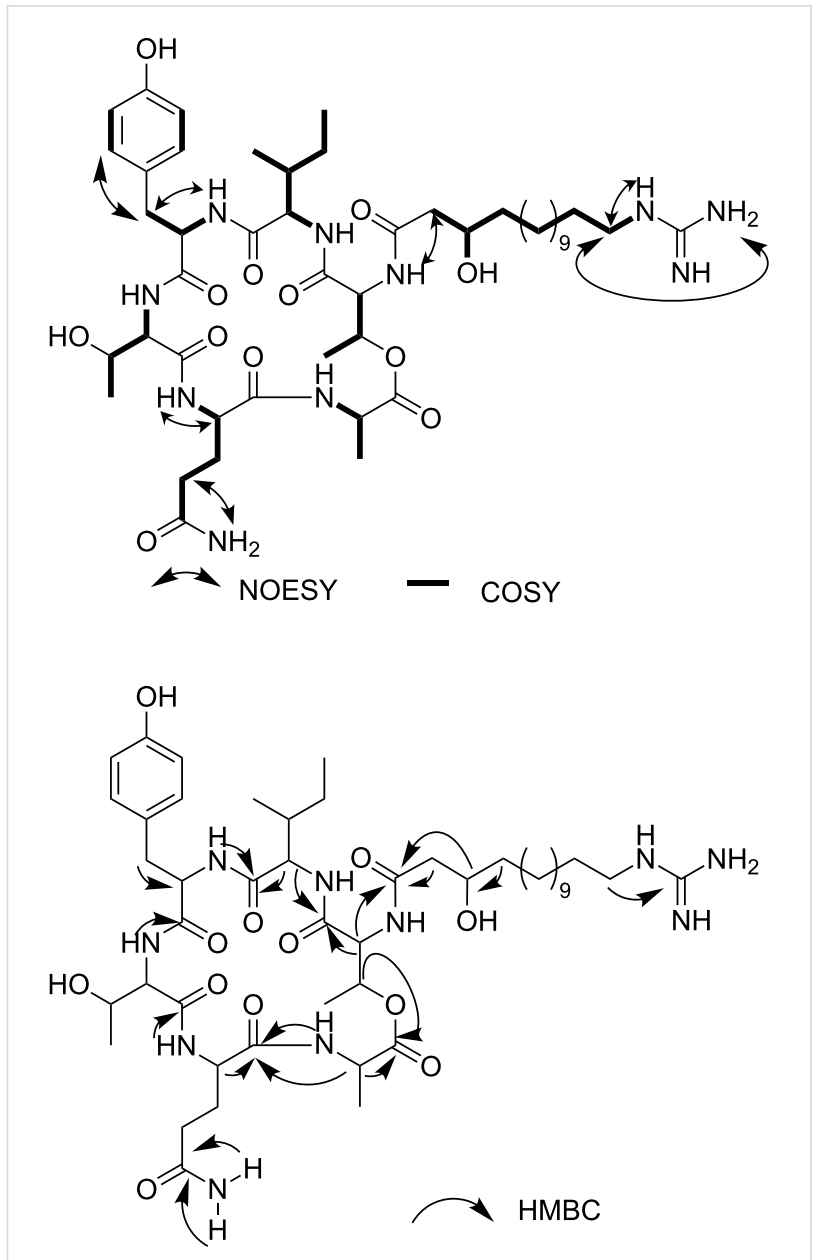

Figure 2: NOESY /COSY and HMBC correlations of compound 1.

The spectra revealed correlations from the Thr2 $\mathrm{NH}$ at $\delta 8.50$ to the $\alpha-\mathrm{CH}$ of Thr 2 at $\delta 3.94$ and the carbonyl of Tyr at $\delta 166.7$. The same correlations were found for the Tyr NH at $\delta 8.52$, the Tyr $\alpha-\mathrm{CH}$ at $\delta 2.60$ and the carbonyl of Ile at $\delta 170.4$. The spectra also showed a strong correlation of the Ile $\alpha-\mathrm{CH}$ at $\delta 4.16$ with the carbonyl signal of Ile at $\delta 170.4$ and a weak correlation with the carbonyl of Thr1 at $\delta$ 168.6. Furthermore, the $\beta$-methine proton at $\delta 5.30$ of Thr1 correlated with the carbonyl signal at $\delta 170.4$ of Ala and additionally the $\mathrm{NH}$ of Ala at $\delta 7.27$ had the expected contact with Ala's $\alpha-\mathrm{CH}$ at $\delta 4.20$. The latter proton showed correlations with the carbonyl of the same amino acid and the one of Gln. The NH proton of Gln at $\delta 8.20$ displayed correlations with the methine hydrogen of Gln at $\delta 3.87$ and the carbonyl of Thr2 at $\delta 170.6$. All data suggested a cyclodepsipeptidic structure for $\mathbf{1}$. The $\mathrm{N}$-atom of Thr1 was bound to a guanidine $\beta$-hydroxy fatty acid as a key correlation was observed between the signal of its $\alpha$-methine proton at $\delta 4.46$ and the resonance of a carbonyl at $\delta 171.9$. This carbonyl showed HMBC correlation with $\alpha$-methylene protons at $\delta 2.35$ and the $\beta$-methine proton at $\delta 3.77$. Additionally correlations between methylene protons at $\delta 3.03$ and the guanidine carbon at $\delta 157.2$ were found. The length of the side chain between the $\beta$-hydroxy and the guanidine group was affirmed by the fragment ion observed in the APCI-MS-MS spectrum of the parent $[\mathrm{M}+\mathrm{H}]^{+}$ion at $m / z$ 256.2. Likewise, this spectrum provided information (Figure 3 ) which confirmed the connection sequence of amino acids and led to elucidate the structure of $\mathbf{1}$ and $\mathbf{2}$ as shown below.

Signals of geminal hydrogen atoms at $\delta 2.80,2.52$ revealed a direct correlation with the carbon atom $\delta 36.3$ in the HSQC spectrum. Based on long-range $\mathrm{H}-\mathrm{H}$ and $\mathrm{H}-\mathrm{C}$ interactions, these resonances were assigned to the $\beta-\mathrm{CH}_{2}$ group of asparagine (Asn) in the lower homologue 2 . Thus, the conclusion was supported by reported data for Asn in other fusaricidins [9] in conjunction to fragments obtained from the tandem mass of the parent peak at $\mathrm{m} / \mathrm{z} 961.6$ (Figure 3).

\section{Retrosynthetic plan}

For our synthesis, a novel and efficient access to the GHPD side chain starting from erucamide (6) as an inexpensive natural source for the required $\mathrm{C}_{13}$-fragment was developed. After ozonolysis of the Fmoc-protected amine obtained by reduction and alkoxycarbonylation from $\mathbf{6}$, the stereocenter should be generated by nucleophilic addition of an allyl anion equivalent to the resulting aldehyde $\mathbf{5}$.

Guanidine formation and ozonolysis with subsequent oxidation to the carboxylic acid would then furnish the protected GHPD side chain building block 3 which can then be coupled to the cyclodepsipeptide fragment to give the desired product $\mathbf{1}$ (Scheme 1). For the synthesis of the cyclodepsipeptide portion, a convergent route was envisaged in which the complete GHPD side chain should be attached in solution after assembly of the cyclodepsipeptide on solid support. The hitherto only published synthesis of a natural fusaricidin by the Jolliffe group employed a ring closure via a lactonization in solution and subsequent attachment of the side chain to the cyclized depsipeptide [10]. Since the macrolactonization approach suffered from diastereoselectivity issues and low yield, it was decided to perform an on-resin head-to-tail macrolactamization instead [11]. A similar strategy had been used by Cudic and co-workers to synthesize analogs of fusaricidin A with an on resin coupling of a 12-aminododecanoic acid combined with a late stage guani- 


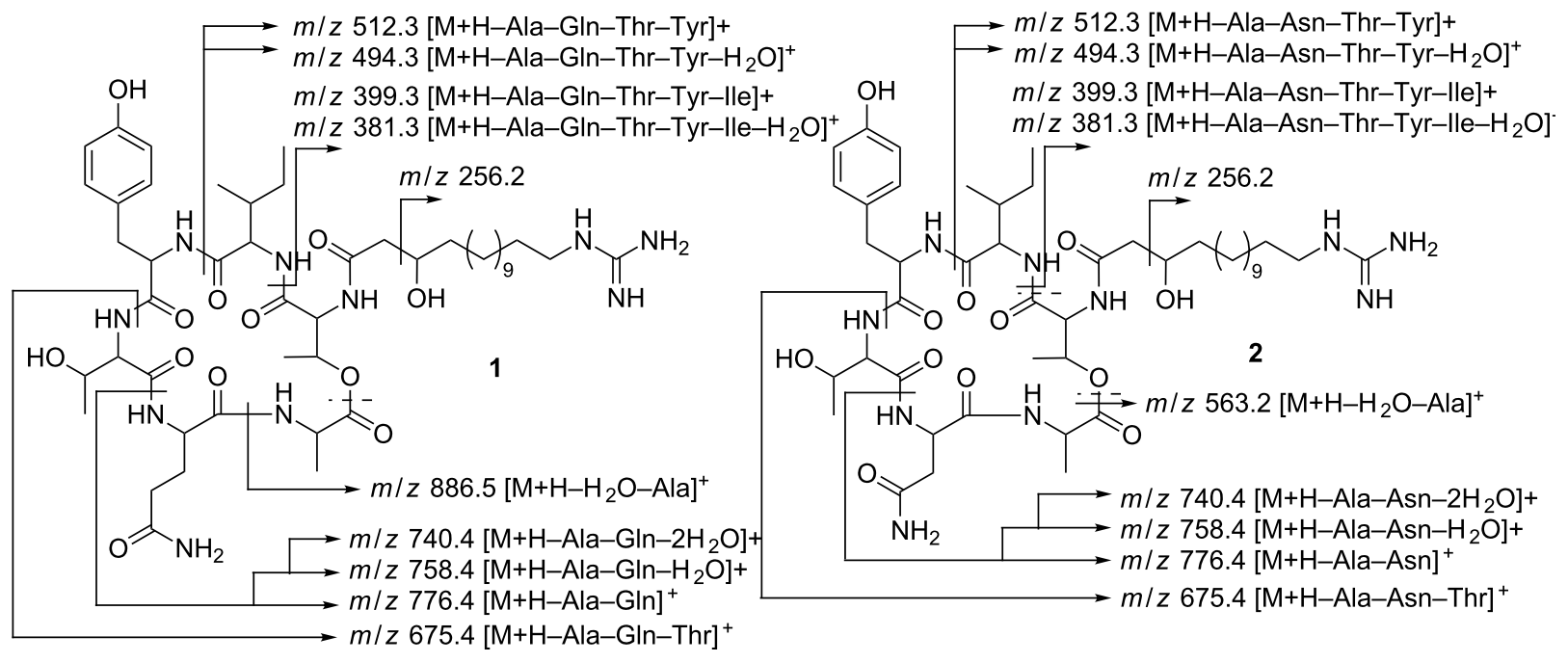

Figure 3: Fragmentation pattern of compounds 1 and 2.

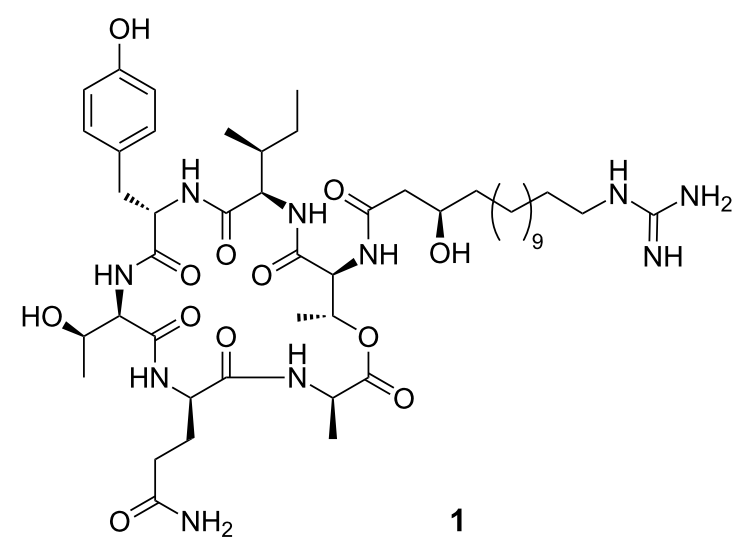<smiles>C=CCNC(=NCCCC(C)(C)CCC(CC(=O)O)OCOC)NC(=O)OCc1ccccc1</smiles><smiles>[3H]C(N)[C@H](N)C(=O)O[C@H](C)C(=O)N[C@H](C(=O)N[C@@H](Cc1ccc(O)cc1)C(=O)N[C@H](CCC(N)=O)C(=O)N[C@@H](CCC(N)=O)C(C)O)C(C)CC</smiles>

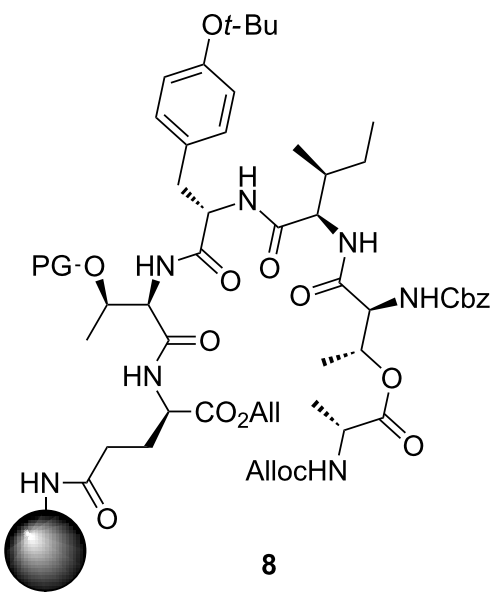<smiles>C=CC[C@@H](CCC(C)(C)CCNC=O)OC</smiles>

4

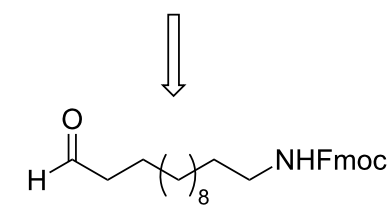

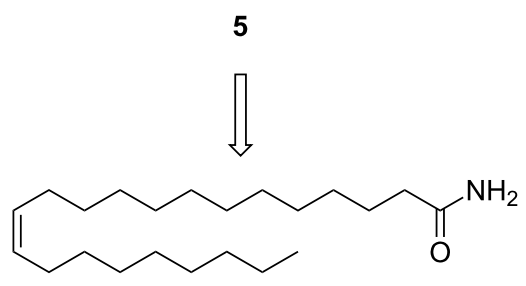


dinylation to give the unnatural 12-guanidinyldodecanoic acid side chain [12]. In order to reduce the number of linear steps, the protected guanidino group was included in the side chain building block in our case. This strategy would allow to assemble the complete peptide core in a solid-phase synthesis and to perform the solution-phase coupling without a large excess of the GHPD side chain building block. Thus, Cudic's SPPS approach should be combined with the advantages of the late stage coupling employed by Jolliffe.

\section{Synthesis}

The $\mathrm{C}_{13}$-fragment was prepared starting from erucamide (6) in three simple operations. Reduction of the amide with lithium aluminium hydride, followed by Fmoc-protection and ozonolysis furnished aldehyde 5 in 57\% yield over three steps (Scheme 2).

The homoallylic alcohol was prepared by an enantioselective Duthaler-Hafner allylation [13] with the titanium-complex $\mathbf{1 5}$ in high yield and $94 \%$ ee. Attempts to perform a catalytic Keck allylation with BINOL-titanium catalysts failed due to low conversion [14]; however, in spite of good experience with the
Maruoka-Keck allylation in another total synthesis, the conversion was not satisfying in this case [15]. After protection and guanidinylation with triflylguanidine $\mathbf{1 4}$, the homoallylic alcohol 12 was subjected to ozonolysis and Pinnick oxidation to furnish the protected GHPD acid 3 in an overall yield of $14.3 \%$.

The peptide core was synthesized manually according to a standard SPPS Fmoc protocol using HATU and NMM in NMP [16]. For protection of the threonine unit, it was converted into a 2,2-dimethylated pseudoproline ( $\left.\Psi^{\mathrm{Me}, \mathrm{Me}} \mathrm{Pro}\right)$. This method has been reported to improve yields of macrolactamizations through stabilizing the cis-configuration of the amide bond and working as a turn inducer in peptides [17-20]. The $\Psi^{\mathrm{Me}, \mathrm{Me}}$ Pro unit turned out not to be completely stable during the esterification with DIC/DMAP [12] as the double acylation product $\mathbf{1 8}$ could be detected (Scheme 3 ).

Further investigations suggested DMAP to be responsible for the cleavage of the $\Psi^{\mathrm{Me}}, \mathrm{Me}$ 'Pro and after reduction of the amount of DMAP to $5 \mathrm{~mol} \%$, nearly no doubly acylated product was found.<smiles>CCCCCCCCCCCCCCCCCC(N)=O</smiles>

6

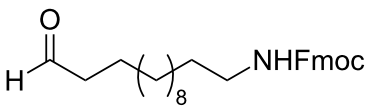

5

$\downarrow$<smiles>C=CC[C@H](O)CCCCCCNC=COC</smiles>

11<smiles>CCCCC(=O)NC(=N[Mg])NC(=O)OCc1ccccc1</smiles>

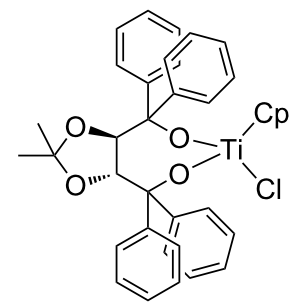

15

a)

c)<smiles>CCCCCCCCCCCCCCCCC/C=C\CCCCN</smiles>

b)<smiles>CCCCCCCCCCCCCCCCNC=O</smiles>

e), f), g)<smiles>C=CC[C@@H](CCCCCCNC(=NC(=O)OC(C)(C)C)OC(C)(C)C)OCOC</smiles>

h)<smiles>[R]CC[R](=O)CC[C@@H](CC([R])=O)OCOC</smiles>

Scheme 2: a) $\mathrm{LiAlH}_{4}$, THF, reflux, $12 \mathrm{~h}$, quant.; b) Fmoc-OSu, $\mathrm{NaHCO}_{3}, 1,4$-dioxane, $\mathrm{H}_{2} \mathrm{O}, 0{ }^{\circ} \mathrm{C}$ to rt, $87 \%$; c) $1: \mathrm{O}_{3}, \mathrm{DCM},-78{ }^{\circ} \mathrm{C}, 2: \mathrm{Zn}, \mathrm{HOAC}$, $-78{ }^{\circ} \mathrm{C}$ to $10{ }^{\circ} \mathrm{C}, 66 \%$; d) allylmagnesium chloride, $15, \mathrm{Et}_{2} \mathrm{O},-78{ }^{\circ} \mathrm{C}, 84 \%, 94 \%$ ee; e) MOMCI, DIPEA, DCM $0{ }^{\circ} \mathrm{C}$ to rt; f) piperidine, DCM, rt; g) 14 , $\mathrm{NEt}_{3}, \mathrm{DCM}, 49 \%$ (over 3 steps); h) 1: $\mathrm{O}_{3}, \mathrm{DCM},-78{ }^{\circ} \mathrm{C}, 2: \mathrm{PPh}_{3},-78{ }^{\circ} \mathrm{C} \rightarrow \mathrm{rt}, 77 \%$; i) $\mathrm{NaClO}_{2}, \mathrm{NaH}_{2} \mathrm{PO}_{4}$, amylene, $t-\mathrm{BuOH}, \mathrm{H} \mathrm{O} \mathrm{O}, \mathrm{rt}, 80 \%$. 


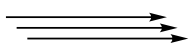

Tentagel R RAM

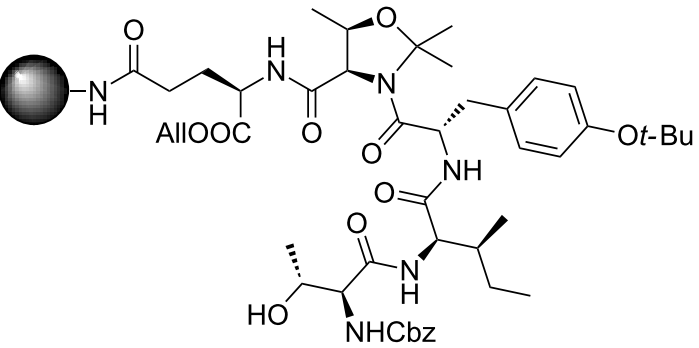

16

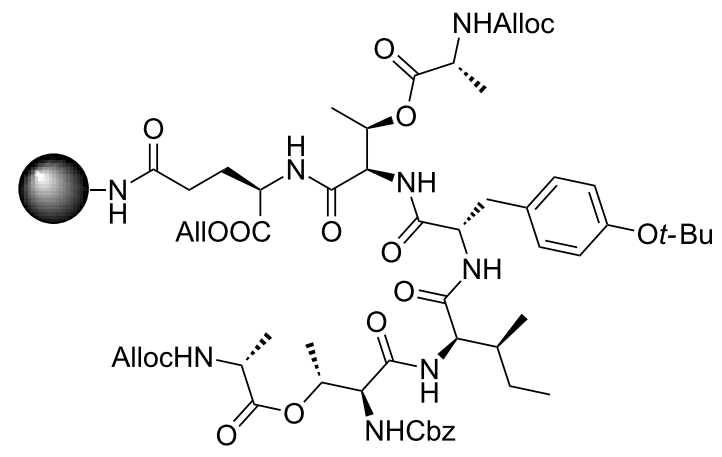

18

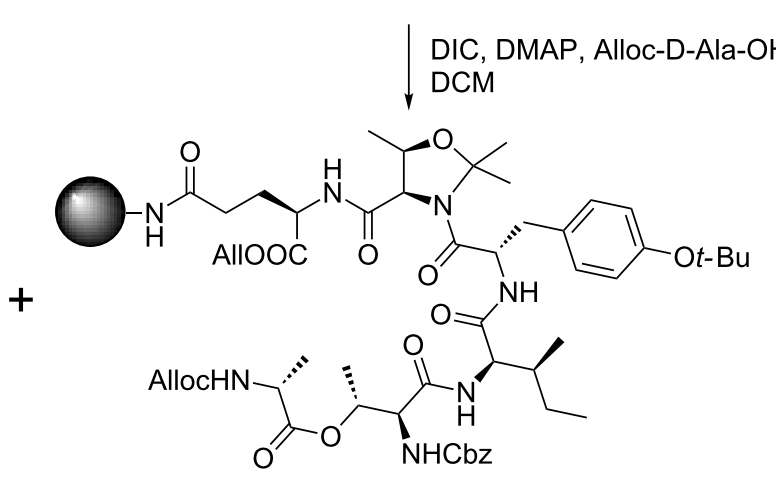

17

Scheme 3: Ester bond formation with 2,2-dimethylated pseudoproline including peptide 16.

Besides the doubly acylated product, several other uncharacterized byproducts were formed. Nevertheless, $O$-deallylation with $\mathrm{Pd}\left(\mathrm{PPh}_{3}\right)_{4}$ and $\mathrm{BH}_{3} \cdot \mathrm{NHMe}_{2}$ gave a high conversion to the deprotected peptide [1]. The cyclization with PyBOP, HOBt and DIPEA in DMF led again to the formation of numerous byproducts. In contrast to literature reports [12], it was found that cleavage from the resin with "reagent $\mathrm{K}$ " $[12,21]$ was inferior to a TFA/TIS/ $\mathrm{H}_{2} \mathrm{O}$ mixture $(95: 2.5: 2.5)$. Due to the instability of $\Psi \mathrm{Me}, \mathrm{Me}$ 'Pro during esterification and cyclization, the isolated yield of 19 was only 6\% (Scheme 4).

To improve this, O-tert-butyl-protected D-allo-Thr was employed instead. For the O-tert-butyl-protected D-allo-Thr, clean and complete conversion was observed during both esterification and deprotection. This time, cyclization was performed with PyAOP and NMM in NMP to provide 19 in an isolated yield of $37 \%$ (Scheme 5 ).

Unfortunately, we observed two signal sets in NMR spectra (intensity $3: 1$ ) for the product which could not be attributed to conformers or rotamers as evidenced by variable temperature and NOESY NMR experiments.

These results, and the fact that Cochrane also reported problems due to epimerization during macrolactonization suggested that a partial loss of stereochemical integrity had taken place during either cyclization or esterification [11]. The site of epi-

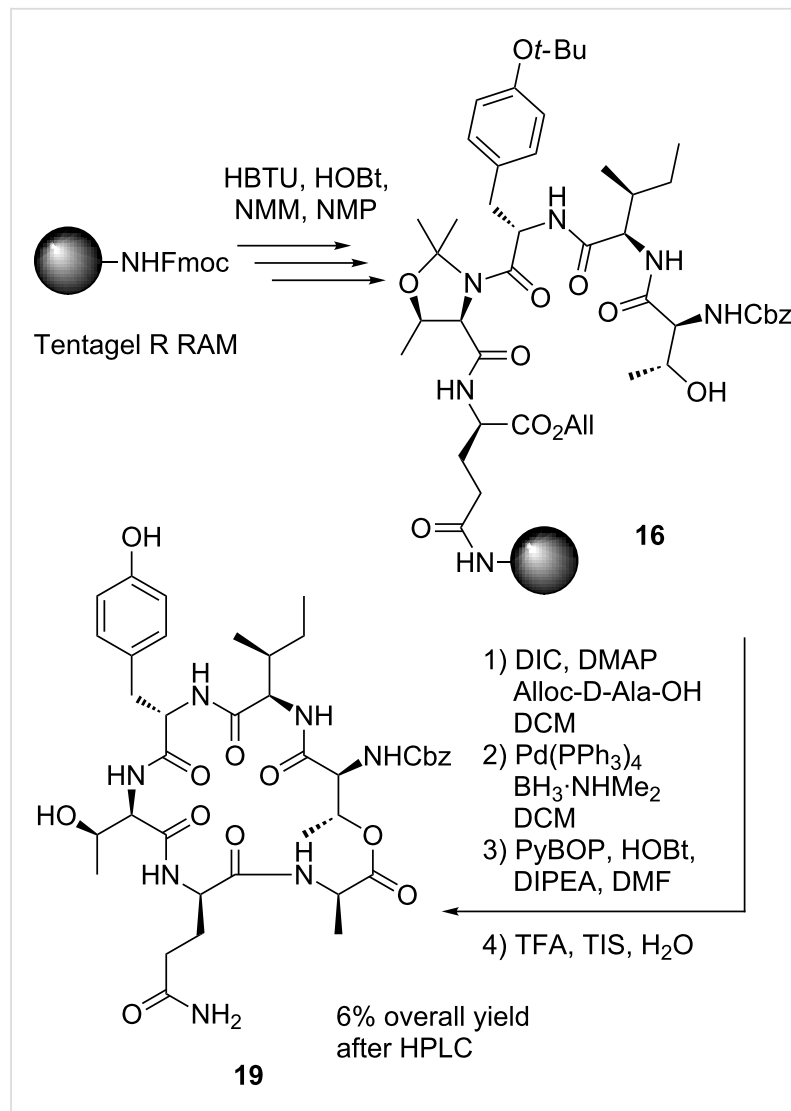

Scheme 4: Cyclization with 2,2-dimethylated pseudoproline including peptide 16. 


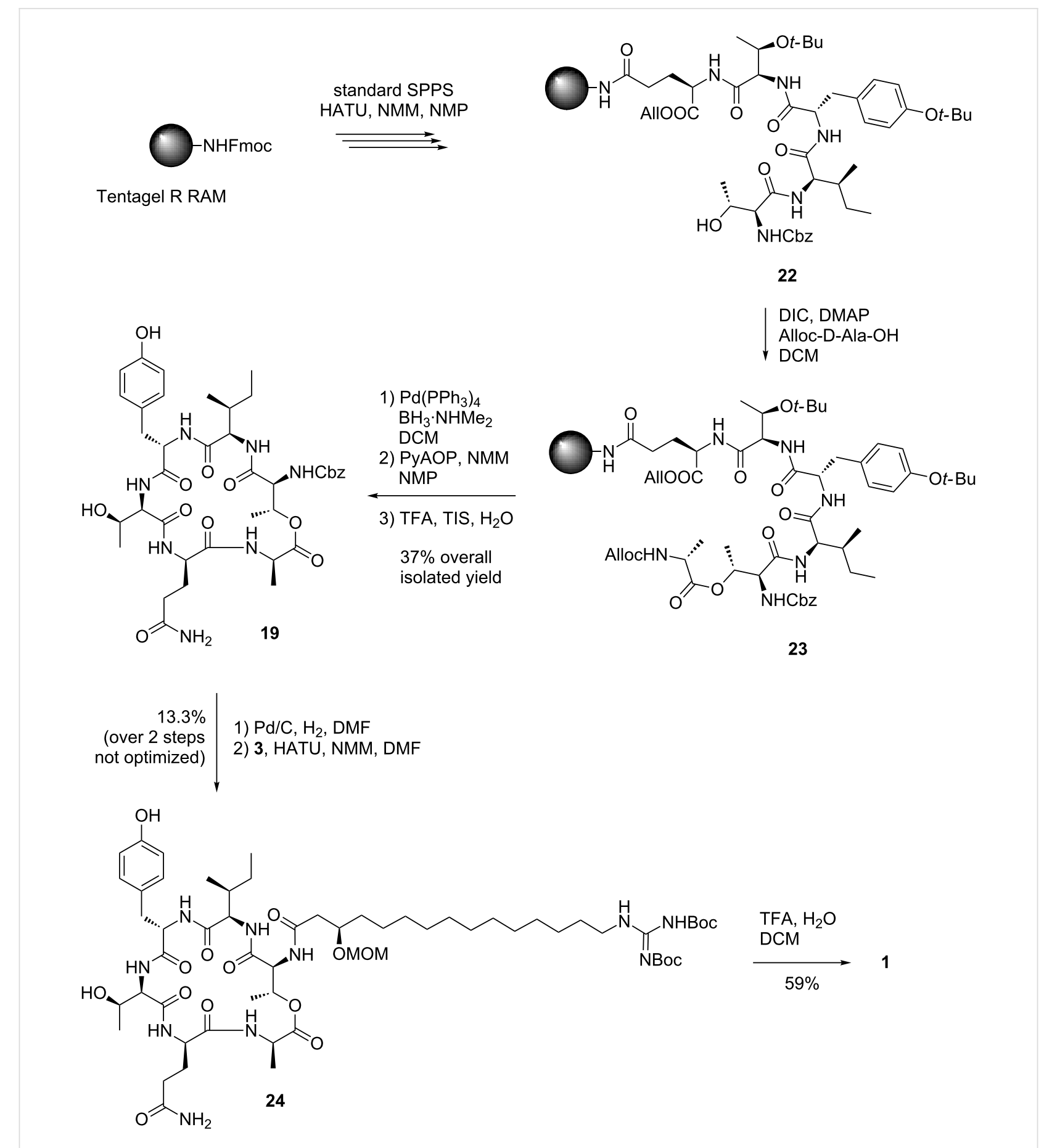

Scheme 5: Depsipeptide cyclization and coupling with GHPD side chain.

merization could not be determined with certainty, but most likely, the D-Ala residue was affected.

As the assumed diastereomers could not be observed or separated by HPLC, the next steps were performed with the mixture. Performing the removal of the $\mathrm{Cbz}$ group with $\mathrm{H}_{2} / \mathrm{Pd}-\mathrm{C}$ in THF, we encountered the formation of the $N$-(4-hydroxybutylated) product 25 resulting from a ring opening reaction of the solvent (Figure 4). This side reaction has been reported for unstabilized THF [22] while stabilized THF was used in our case.

Due to solubility problems in 1,4-dioxane and other solvents suitable for hydrogenolysis, the deprotection was thus performed in DMF [23,24]. Unfortunately, an $O \rightarrow N$ acyl shift to 
<smiles>CCC(C)[C@H](NC(=O)[C@H](NCCCCO)[C@H](C)OC(=O)[C@H](C)NC(=O)[C@H](CCC(N)=O)NC(=O)[C@H](Cc1ccc(O)cc1)NC(=O)[C@H](C)O)C(C)O</smiles><smiles>CCC(C)[C@H](NC(=O)[C@H](NC(=O)[C@H](C)NC(=O)[C@H](Cc1ccc(O)cc1)NC(=O)[C@H](NC(=O)[C@H](CCC(N)=O)NC(=O)[C@H](C)O)C(C)O)C(C)O)C(=O)N[C@@H](C)CC</smiles>

Figure 4: Byproducts from removal of $\mathrm{Cbz}$ group in THF and DMF

product $\mathbf{2 6}$ could be observed as judged by NMR spectroscopy when aged DMF was used for this purpose. In fresh DMF, hydrogenolysis smoothly produced amine 7 instead. When the crude peptide was coupled to the GHPD side chain unit $\mathbf{3}$, HPLC showed only a single peak with the correct $m / z$ ratio. This compound $\mathbf{2 4}$ was isolated by preparative HPLC and NMR analysis showed a single signal set, so the fate of the assumed minor stereoisomer remains unclear and it was probably lost during HPLC purification. The analysis also revealed that the acylation with the GHPD side chain was selective for the amine and no $O$-acylated product was formed. Side chain protecting groups were removed to yield the natural product 1. HPLC analysis showed only a single peak with the same retention time, mass and fragmentation pattern as the natural product. After purification by preparative HPLC, NMR spectroscopy confirmed that the assumed structure and stereochemistry of the natural product was correct (see pages S38 and S39 of Supporting Information File 1).

\section{Conclusion}

In summary, two new members of the fusaricidin family, fusaricidins E and F, were isolated from fermentation broths of Paenibacillus sp. strain Lu16774 as an inseparable mixture of homologs. Structure elucidation of both peptides was per- formed with extensive NMR spectroscopy and tandem mass spectrometry. The full stereostructure of the major component, fusaricidin E, could be confirmed by total synthesis. It included a macrolactamization approach combined with a late stage attachment of the GHPD side chain which was synthesized by a newly developed and efficient sequence starting from erucamide. Compared to the Jolliffe strategy, yields were improved and the number of solution phase transformations was reduced. On the other hand, the yields of the Cudic synthesis could not be reached and more steps required purification of the respective products.

\section{Supporting Information}

\section{Supporting Information File 1}

Procedures for the synthesis and characterisation data of the compounds.

[http://www.beilstein-journals.org/bjoc/content/ supplementary/1860-5397-13-140-S1.pdf]

\section{Acknowledgements}

This work was supported by the Rhineland Palatinate Center for Natural Products Research as well as by BASF SE. We thank Dr. J. C. Liermann (Mainz) for NMR spectroscopy and Dr. N. Hanold (Mainz) for mass spectrometry.

\section{References}

1. Bionda, N.; Stawikowski, M.; Stawikowska, R.; Cudic, M.; López-Vallejo, F.; Treitl, D.; Medina-Franco, J.; Cudic, P. ChemMedChem 2012, 7, 871-882. doi:10.1002/cmdc.201200016

2. Li, J.; Jensen, S. E. Chem. Biol. 2008, 15, 118-127. doi:10.1016/j.chembiol.2007.12.014

3. Han, J. W.; Kim, E. Y.; Lee, J. M.; Kim, Y. S.; Bang, E.; Kim, B. S. Biotechnol. Lett. 2012, 34, 1327-1334. doi:10.1007/s10529-012-0913-8

4. Vater, J.; Niu, B.; Dietel, K.; Borriss, R. J. Am. Soc. Mass Spectrom. 2015, 26, 1548-1558. doi:10.1007/s13361-015-1130-1

5. Kurusu, K.; Ohba, K.; Arai, T.; Fukushima, K. J. Antibiot. 1987, 40, 1506-1514. doi:10.7164/antibiotics.40.1506

6. Kajimura, Y.; Kaneda, M. J. Antibiot. 1996, 49, 129-135. doi:10.7164/antibiotics.49.129

7. Kajimura, Y.; Kaneda, M. J. Antibiot. 1997, 50, 220-228. doi:10.7164/antibiotics.50.220

8. Siepe, I.; Büser, H.; Klappach, K.; Schneider, K. H.; Spröte, P.; Hage, K.; Blanz, B.; Thines, E.; Antelo, L.; Sandjo, L. P. Antifungal paenibacillus strains, fusaricidin-type compounds, and their use. WO Patent WO2016020371, Feb 2, 2016.

9. Kuroda, J.; Fukai, T.; Konishi, M.; Uno, J.; Kurusu, K.; Nomura, T. Heterocycles 2000, 53, 1533-1549. doi:10.3987/COM-00-8922

10. Cochrane, J. R.; McErlean, C. S. P.; Jolliffe, K. A. Org. Lett. 2010, 12, 3394-3397. doi:10.1021/ol101254m

11. Cochrane, J. R.; Yoon, D. H.; McErlean, C. S. P.; Jolliffe, K. A. Beilstein J. Org. Chem. 2012, 8, 1344-1351. doi:10.3762/bjoc.8.154 
12. Stawikowski, M.; Cudic, P. Tetrahedron Lett. 2006, 47, 8587-8590. doi:10.1016/j.tetlet.2006.09.116

13. Hafner, A.; Duthaler, R. O.; Marti, R.; Rihs, G.; Rothe-Streit, P.; Schwarzenbach, F. J. Am. Chem. Soc. 1992, 114, 2321-2336. doi:10.1021/ja00033a005

14. Hanawa, H.; Uraguchi, D.; Konishi, S.; Hashimoto, T.; Maruoka, K. Chem. - Eur. J. 2003, 9, 4405-4413. doi:10.1002/chem.200305078

15. Götz, K.; Liermann, J. C.; Thines, E.; Anke, H.; Opatz, T. Org. Biomol. Chem. 2010, 8, 2123-2130. doi:10.1039/c001794a

16. Chan, W.; White, P. Fmoc Solid Phase Peptide Synthesis: A Practical Approach; Oxford University Press: Oxford, 2000.

17. Skropeta, D.; Jolliffe, K. A.; Turner, P. J. Org. Chem. 2004, 69, 8804-8809. doi:10.1021/jo0484732

18. Sayyadi, N.; Skropeta, D.; Jolliffe, K. A. Org. Lett. 2005, 7, 5497-5499. doi:10.1021/ol0522891

19. Dumy, P.; Keller, M.; Ryan, D. E.; Rohwedder, B.; Wöhr, T.; Mutter, M. J. Am. Chem. Soc. 1997, 119, 918-925. doi:10.1021/ja962780a

20. Fairweather, K. A.; Sayyadi, N.; Luck, I. J.; Clegg, J. K.; Jolliffe, K. A. Org. Lett. 2010, 12, 3136-3139. doi:10.1021/ol101018w

21. Jubilut, G. N.; Cilli, E. M.; Crusca, E., Jr.; Silva, E. H.; Okada, Y.; Nakaie, C. R. Chem. Pharm. Bull. 2007, 55, 468-470. doi:10.1248/cpb.55.468

22. Russell, H. F.; Bremner, J. B.; Bushelle-Edghill, J.; Lewis, M. R.; Thomas, S. R.; Bates, F., II. Tetrahedron Lett. 2007, 48, 1637-1639. doi:10.1016/j.tetlet.2006.12.136

23. Greven, H. M.; van Nispen, J. W.; Bijl, W. A. A. J. Recl. Trav. Chim. Pays-Bas 1980, 99, 284-286. doi:10.1002/recl.19800990909

24. Fukami, T.; Niiyama, K.; Amano, Y.; Hisaka, A.; Fujino, N.; Sawasaki, Y.; Ihara, M.; Ishikawa, K. Chem. Pharm. Bull. 1996, 44, 609-614. doi:10.1248/cpb.44.609

\section{License and Terms}

This is an Open Access article under the terms of the Creative Commons Attribution License (http://creativecommons.org/licenses/by/4.0), which permits unrestricted use, distribution, and reproduction in any medium, provided the original work is properly cited.

The license is subject to the Beilstein Journal of Organic Chemistry terms and conditions:

(http://www.beilstein-journals.org/bjoc)

The definitive version of this article is the electronic one which can be found at: doi:10.3762/bjoc. 13.140 